\title{
Desenvolvimento da Linguagem Oral e da Memória de Trabalho em Indivíduos com Síndrome de Down por meio da Recontagem de Histórias
}

\author{
Amanda Avelar Lima ${ }^{1}$; Carla Salati Almeida Ghirello-Pires ${ }^{2}$
}

\begin{abstract}
Resumo: O objetivo foi analisar o efeito da expansão da linguagem oral em indivíduos com Síndrome de Down, através da avaliação e intervenção da memória de trabalho, por meio da recontagem de histórias. Os participantes foram selecionados no Laboratório de Estudos e Pesquisa em Neurolinguística (LAPEN), localizado na Universidade Estadual da Bahia (UESB) em Vitória da Conquista - Bahia, sendo 4 indivíduos com Síndrome de Down com 8 anos (AR e SB) e 12 anos (CP e LR), sexo feminino. A pesquisa contou com três fases: a avaliação inicial da memória de trabalho; a estimulação da memória de trabalho e da linguagem, através da contagem e recontagem de histórias; e a avaliação final da memória de trabalho. Os resultados indicaram melhores desempenhos dos participantes na avaliação final da memória de trabalho em comparação à avaliação inicial. As evidencias apontaram que o processo interventivo, através das narrativas, favoreceu um melhor desempenho na memória de trabalho e na expansão linguística.
\end{abstract}

Palavras Chaves: Memória de Trabalho. Linguagem Oral. Síndrome de Down.

\section{Development of Oral Language and Working Memory in Individuals with Down's Syndrome by Recounting Histories}

\begin{abstract}
This study aims to analyze the effect of the expansion of oral language in individuals with Down's Syndrome, through the evaluation and intervention of working memory through the recounting of stories. The research has qualitative character. The participants were selected in the Laboratory of Neurolinguistic Studies and Research (LAPEN) located at the State University of Bahia (UESB) in Vitória da Conquista - Bahia, four children / pre-adolescents with down syndrome, female, aged 8 and 12 years. The research had three phases: the evaluation of working memory; cognitive stimulation by counting and recounting stories with the quantification of interventions performed by the researcher; reassessment after the stimulation process. The results confirmed the initial hypothesis of the effectiveness of the intervention process of working memory stimulation through mediation in interrelation with the appropriation and maintenance of language.
\end{abstract}

Keywords: Work Memory. Oral Language. Down's syndrome.

\footnotetext{
${ }^{1}$ Mestre em Linguística pelo Programa de Pós-graduação em Linguística (PPGLin) da Universidade Estadual do Sudoeste da Bahia (UESB) (2018). Graduação em Psicologia pela Universidade Federal da Bahia (UFBA) (2015). E-mail: amandaavelarvcba@gmail.com.

${ }^{2}$ Pós-doutorado em Psicologia pelo Programa de Pós-graduação em Psicologia da Universidade Estadual de Maringá (UEM) (2016). Doutora em Linguística -Neurolinguística - pelo Instituto de Estudos Linguístico da Universidade Estadual de Campinas (UNICAMP) (2006). Mestre em Psicologia pelo Instituto de Psicologia da Universidade São Paulo (USP) (1997). Docente do Departamento de Estudos Linguísticos e Literários (DEEL) da Universidade Estadual do Sudoeste da Bahia (UESB) e do Programa de Pós-graduação em Linguística (PPGLin) da UESB. E-mail: carlaghipires@ hotmail.com.
} 


\section{Introdução}

A síndrome de Down (SD), ou Trissomia do 21, foi descrita primeiramente por Down (1866), médico inglês, como uma alteração cromossômica, caracterizada pela presença de um cromossomo extra ligado ao par 21, sendo a principal causa de deficiência intelectual. O Sistema Nervoso Central (SNC) do indivíduo com SD apresenta anormalidades estruturais e funcionais, que acarretam dificuldades cognitivas, principalmente, na memória e na linguagem. As alterações na estrutura cerebral, como tamanho encefálico, geralmente $3 \%$ inferior quando comparado aos dados padronizados referentes às crianças normais (KOZMA, 2007); redução volumétrica das áreas frontais e cerebelares (TRONCOSO; CERRO, 1999), com redução no lóbulo temporal em até 50\% dos casos (SILVA; KLEINHANS, 2006), e diminuição do corpo caloso e do hipocampo nos dois hemisférios (PINTER, 2001). Essas estruturas são responsáveis pela codificação e integração das informações em sujeitos com $\mathrm{SD}$, e poderiam explicar os episódios de déficit de memória e de linguagem.

Além disso, esses indivíduos exibem deficiências nas ramificações dendríticas, com diminuição dos neurônios responsáveis pela conduta associativa e pela comunicação entre as áreas cerebrais (TRONCOSO; CERRO, 1999). A influência que essas alterações exercem sobre o desenvolvimento inicial, nos circuitos cerebrais, afeta a instalação e as consolidações das conexões de redes nervosas necessárias para estabelecer os mecanismos da atenção, memória, percepção, raciocínio, velocidade de processamento e pensamento lógico.

É imprescindível considerar que o SNC possui uma capacidade de transformação e adaptação em resposta às exigências ambientais e internas, e isso faz com que exista reorganização e regeneração para uma determinada dificuldade que o sujeito apresente na realização de alguma tarefa externa. Segundo Sales e Konkiewitz (2010), o sistema nervoso não é uma estrutura rígida e imutável, mas sim flexível, que modifica sua estrutura funcional sob diferentes circunstâncias, expressando, assim, uma capacidade plástica durante o processo de adaptação. As considerações sobre a dinâmica do SNC e as questões de neuroplasticidade levam a considerar a importância de programas de estimulação cognitiva, com a finalidade da reorganização cerebral naqueles indivíduos com o desenvolvimento cerebral atípico.

Os indivíduos com SD apresentam um atraso no desenvolvimento global que se manifesta, sobretudo, na aquisição e desenvolvimento da linguagem oral e escrita. A área da linguagem é a área na qual exibe maior atraso (SCHWARTZMAN, 1999; CUNNINGHAM,

213 Id on Line Rev. Mult. Psic. V.13, N. 46 p. 212-230, 2019 - ISSN 1981-1179 Edição eletrônica em http://idonline.emnuvens.com.br/id 
2008). As crianças com SD mostram dificuldades em reconhecer regras gramaticais e sintáticas da língua, além de dificuldades na produção da fala com o desemparelhamento entre a velocidade com que se compreende e o ato de falar propriamente dito (BISSOTO, 2005). Assim, Ghirello-Pires (2012) afirma que os sujeitos com SD, apesar de serem considerados de risco para a aquisição e desenvolvimento da linguagem, por apresentarem problemas no processamento auditivo, hipotonia e de déficits cognitivos, irão passar pelos mesmos processos de aquisição da linguagem que qualquer criança típica, porém com atrasos.

$\mathrm{Na}$ memória, os sujeitos com SD apresentam déficits que podem ser notados desde a idade jovem (SILVERMAN, 2007). A maior dificuldade encontrada na trissomia está nos processos mnemônicos de fatos recentes, memória de curto prazo, especialmente, a memória de trabalho. Esta é definida como um sistema que não só armazena informações de forma temporária, manipulando-as de modo a permitir que as pessoas executem atividades complexas, como raciocínio, aprendizado e compreensão (BADDELEY, 2011). A dificuldade na memória de trabalho é expressa também na expansão da linguagem, uma vez que se a memória e a linguagem atuam conjuntamente, seja para a aquisição, consolidação e acesso, há um arquivo mnêmico declarativo, seja para a produção, seja para interpretação de uma elocução.

Sendo assim, Baddeley (2011) propôs o modelo de memória de trabalho, que apresenta os subsistemas: alça fonológica, visuoespacial, executivo central e buffer episódico. A alça fonológica pressupõe um armazenamento temporário de sequências acústicas ou itens baseados na fala, é um modelo de memória verbal de curta duração, que exerce um papel importante no processamento da linguagem. $\mathrm{O}$ esboço visuoespacial, que tem como função armazenar e manipular informações de natureza visual, fazendo a integração das informações visuais e espaciais, apresenta relação com o ato da leitura e da escrita, no que se refere ao processo de codificação do código da língua. Já o executivo central, que funciona como um sistema de controle atencional limitado, controla os outros dois subsistemas de armazenamento. O buffer episódico, último componente a ser inserido no modelo, armazena temporariamente as informações em um código multidimensional, associa os códigos visuoespaciais, fonológicos e os integra na memória de longo prazo.

As pesquisas, que abarcam o tema memória de trabalho em indivíduos com SD, trabalham principalmente com os subsistemas alça fonológica (BADDELEY; JARROLD, 2007; DUARTE, 2009; JARROLD; NADEL; VICARI, 2008) e visuoespaciais (LAWS, 2002;

214 Id on Line Rev. Mult. Psic. V.13, N. 46 p. 212-230, 2019 - ISSN 1981-1179 Edição eletrônica em http://idonline.emnuvens.com.br/id 
JARROL; NADEL; VICARI, 2008; DUARTE, 2009). É consenso nessas pesquisas que os indivíduos com SD têm um desempenho significativamente inferior em provas que avaliam alça fonológica, se comparado às pessoas sem a síndrome, porém com mesmo nível de deficiência intelectual. Além disso, os autores salientam que os sujeitos com SD têm maiores possibilidades de memorização, quando lhes é ofertado o recurso visuoespacial.

Chapman (2006) analisou o desempenho em tarefas envolvendo o subsistema do buffer episódico, sendo essas de repetição de história mediada nos indivíduos com SD. Com isso, o autor afirma que o déficit de memória de trabalho verbal e as dificuldades de linguagem expressiva, durante a narração de histórias, são características do grupo com SD. Entretanto, quando as figuras foram oferecidas como apoio para a narração, a dificuldade de linguagem expressiva diminuiu. Nota-se, pois, que a memória de trabalho está relacionada a diversos aspectos cognitivos, principalmente ao desenvolvimento e expansão da linguagem.

Dessa maneira, as narrativas constituem um meio de análise e intervenção para a memória de trabalho e a internalização linguística. Sendo assim, Perroni (1992) considera as histórias, a partir de uma perspectiva interacional, como um importante recurso na investigação, envolvendo a relação da língua com a construção de significados na interação social, através da análise de narrativa. Na linha da psicologia narrativa, Brunner (2008) argumenta que as histórias fornecem modelos do mundo e que as convenções narrativas são padrões aos quais devem se ajustar, a fim de serem reconhecidas em uma cultura.

O processo de aquisição do discurso narrativo é longo e não acontece antes dos 5 anos de idade, período em que a criança se torna uma narradora proficiente (SCARPA, 2001). A perspectiva processual das narrativas, adotada por Perroni (1992), permite perceber que as produções linguísticas das crianças vão apresentando modificações, a partir da apropriação de recursos, realizados pelas crianças, os quais as tornam mais independentes de seus interlocutores adultos.

Camargo (1994), em sua pesquisa sobre investigação das narrativas infantis em indivíduos com SD, observou que há uma defasagem de linguagem nas crianças com SD no aspecto temporal e/ou a nível simbólico, e a fala do adulto auxilia no discurso narrativo. A autora concluiu que existem diferenças no desempenho narrativo das crianças com SD e que estas perpassam os mesmos mecanismos narrativos que os sujeitos típicos, entretanto em idade cronológica posterior. 
A partir do exposto, o presente estudo objetiva analisar o efeito da expansão da linguagem oral em indivíduos com Síndrome de Down, através da avaliação e intervenção da memória de trabalho por meio da recontagem de histórias. Considera-se, assim, que as tarefas de repetição de história mediada têm como finalidade desenvolver a memória de trabalho em subsistema buffer episódico, na inter-relação com a apropriação e a manutenção da linguagem.

\section{Método}

\section{Participantes}

Os critérios para inclusão dos participantes foram: $1^{\circ}$ ) não apresentar comprometimento auditivo, comprovado por Emissões otoacústicas e Bera; $2^{\circ}$ ) apresentar trissomia no par cromossômico 21 e inteligência com percentil maior que 5\%, avaliado pelo Teste de Matrizes Progressivas de Raven (ANGELINI, et al. 1999). O objetivo de avaliar a inteligência foi estabelecer com que a amostra da pesquisa não apresentasse grande disparidade e um comprometimento grave da inteligência, que poderia prejudicar a análise da intervenção. Além disso, ser acompanhado no grupo de pesquisa "Fala Down", que faz parte do Laboratório de Pesquisa Neurolinguística (LAPEN), localizado no campus da Universidade Estadual do Sudoeste da Bahia (UESB), na cidade de Vitória da Conquista Bahia.

Destes, foram selecionados quatro crianças e adolescentes (AR, SB, CP e LR), sendo todas do sexo feminino, com idades correspondentes de 8 anos (AR e SB) e 12 anos (CP e LR). Na Tabela 1, é demostrado a caracterização dos participantes em relação ao ambiente escolar, todos os participantes estão matriculados no ensino regular, constituindo 3 em escola de rede privada e 1 em escola de rede pública. Quanto à escolaridade do pai, sendo que 3 apresentam o ensino superior e 1 o ensino médio, e à escolaridade da mãe, em que 2 apresentam o ensino superior e 2 o ensino médio. Ademais, na classificação, econômica todos os participantes distribuem de forma fragmentada entre A, A2, B1 e B2. 
Tabela 1 - Caracterização dos participantes

\begin{tabular}{ccc}
\hline & & Participantes \\
\hline Sexo & Masculino & 0 \\
& Feminino & 4 \\
\hline Sistema Escolar & Público & 1 \\
& Privado & 3 \\
\hline Escolaridade do Pai & Ensino Fundamental & - \\
& Ensino Médio & 1 \\
& Ensino Superior & 3 \\
\hline Escolaridade da Mãe & Ensino Fundamental & - \\
& Ensino Médio & 2 \\
& Ensino Superior & 2 \\
\hline Classificação Socioeconômica & A1 & 1 \\
& A2 & 1 \\
& B1 & 1 \\
& B2 & 1 \\
\hline
\end{tabular}

Fonte: dados da pesquisa.

\section{Instrumentos}

Critério de Classificação Econômica Brasil (CCEB): avalia o critério socioeconômico das famílias, com levantamento de características domiciliares (presença e quantidade de alguns itens domiciliares de conforto e grau de escolaridade do chefe de família), classificando-as pelo critério de classes econômicas que varia entre A a E (ABEP, 2012).

Teste das Matrizes Progressivas Coloridas de Raven: constituído de provas nãoverbais de raciocínio lógico, sendo mais direcionado para a avaliação da inteligência fluída e, portanto, sofrendo menor influência de variáveis contextuais (ANGELINI, et. al. 1999).

Teste de Corsi ou Cubos de Corsi: contém uma prancha de madeira com blocos com numeração de 1 a 10. Sendo uma prova de repetição imediata dos números, em que, na ordem direta, o sujeito precisa repeti-los na mesma sequência que a examinadora. Inicialmente, a sequência é de apenas dois números e vai aumentando progressivamente, à medida que o sujeito acerta a resposta (SPINNLER; TOGNONI, 1987).

Teste Infantil de Memória de Trabalho (TIMT): é um instrumento que avalia componentes verbais e visuais da memória de trabalho. Contém seis subtestes relativamente simples, porém a carga de processamento aumenta progressivamente (DUARTE, 2009). 


\section{Procedimentos}

A presente pesquisa foi aprovada pelo Comitê de Ética e Pesquisa da UESB (CAAE 29933144.7000.0055), seguindo as exigências estabelecidas pelo Ministério da Saúde sobre a ética em pesquisa com seres humanos, resolução do Conselho Nacional de Saúde no 196/96. O manejo ético considerou os seguintes passos: os pais foram informados sob a possibilidade de desistir da participação sem nenhum prejuízo para eles ou para a criança; foi assinado um Termo de Cometimento Livre e Esclarecido pelos Pais e foi esclarecido que não haveria nenhum ganho financeiro com a participação. Assim, o processo interventivo foi realizado em um ambiente reservado no LAPEN, para garantir o sigilo das informações.

Após a assinatura do termo de consentimento livre e esclarecido, os pais foram convidados a responder uma ficha de dados pessoais e o questionário socioeconômico CCEB. Além disso, foram informados que cada participante passaria por três fases: a avaliação inicial da memória de trabalho e inteligência; a estimulação da memória de trabalho e linguagem através da contagem e recontagem de histórias, até a avaliação final da memória de trabalho.

A avaliação inicial durou duas sessões individuais, com 40 minutos cada, para avaliação da memória de trabalho e da inteligência. O tempo médio entre a primeira e segunda avaliação foi de 2 meses. Durante esse período, realizou-se a intervenção com a contagem e recontagem de 5 narrativas infantis, a qual necessitou de 5 sessões com duração média de 40 minutos cada, totalizando 3horas30minutos de intervenção para cada criança/adolescente.

O processo de intervenção se deu através da repetição de histórias mediadas. Essas narrativas foram cinco fábulas $(\mathrm{O}$ pulo do gato, $\mathrm{O}$ macaco e a velha, $\mathrm{O}$ ratinho e a lua, $\mathrm{O}$ burro e o sal e O fazendeiro, seu filho e o burro), adaptadas por Cappeli e Dias (2009). Com isso, foi solicitado que cada participante da pesquisa escolhesse a história de sua preferência, e, posteriormente, essa mesma história foi narrada pelo pesquisador. Logo após a contagem da história, foi realizada uma atividade distratora durante 5 minutos. Esta consistia no desvio da atenção da criança/ adolescente para outras atividades, tais como: jogos de memória, quebracabeças, brincadeiras de encaixe. Posteriormente, foi pedido ao participante para que recontasse a história contada pelo pesquisador. No momento da recontagem, o pesquisador interviu quando se fez necessário, com o objetivo de auxiliar o desempenho linguístico dos participantes. As intervenções seguiam-se com perguntas, descrições e comentários dos

218 Id on Line Rev. Mult. Psic. V.13, N. 46 p. 212-230, 2019 - ISSN 1981-1179 Edição eletrônica em http://idonline.emnuvens.com.br/id 
elementos da narrativa, para fazer com que as crianças/adolescentes recordassem do enredo da história, ou seja, as intervenções serviam como link para que os participantes rememorassem os elementos da narrativa. Diante disso, foram quantificadas as intervenções realizadas pelo pesquisador, quanto ao desempenho de cada participante. A todo momento, durante a recontagem, o pesquisador reforçou socialmente (elogios, sorrisos) o comportamento de recontar a história.

\section{Análise dos dados}

A análise dos dados ocorreu em duas etapas. Na primeira etapa, foram analisadas as intervenções realizadas com cada participante, e para a apreciação, os dados foram filmados, transcritos e categorizados, sinalizando o desempenho linguístico de cada sujeito. A transcrição foi realizada, seguindo a adaptação da tabela proposta pelo Banco de dados em Neurolinguística (BDN), de que constam quatro colunas: sigla dos integrantes das situações; transcrição; observações sobre as condições de produção do enunciado e gestos/ expressões faciais que utilizamos para apresentação e análise das situações comunicativas e dos eventos comunicativos, bem como dos repertórios comunicativos.

Na segunda etapa do estudo, os dados descritivos da avaliação pré e pós a intervenção foram ponderados, utilizando procedimentos de análise descritiva e de comparação entre a avaliação inicial e a final.

\section{Resultados}

Com o objetivo de identificar a eficácia do processo interventivo da memória de trabalho e linguagem oral, através das narrativas infantis em indivíduos com SD, compararam-se os escores da avaliação de memória de trabalho inicial e a final. Além de quantificar as intervenções realizadas pelo pesquisador no momento de recontagem das narrativas, a Tabela 2 ressalta a distribuição da pontuação na avaliação inicial e final e a quantidade de intervenções realizadas pelo pesquisador (Ia) na recontagem das cinco histórias. 
Tabela 2 - Distribuição da pontuação na avaliação inicial e final e número de intervenções

\begin{tabular}{|c|c|c|c|c|c|c|c|c|c|}
\hline & \multirow{2}{*}{$\begin{array}{c}\text { Sujeito } \\
\text { Tarefa/Intervenção }\end{array}$} & \multicolumn{2}{|c|}{$\mathbf{C P}$} & \multicolumn{2}{|c|}{ SB } & \multicolumn{2}{|c|}{$\mathbf{A R}$} & \multicolumn{2}{|c|}{ LR } \\
\hline & & Antes & Depois & Antes & Depois & Antes & Depois & Antes & Depois \\
\hline \multirow{8}{*}{$\begin{array}{c}\text { Teste } \\
\text { Infantil } \\
\text { de } \\
\text { Memória } \\
\text { de } \\
\text { Trabalho }\end{array}$} & Cubos Corsi & 0 & 2 & 1 & 2 & 2 & 3 & 2 & 4 \\
\hline & Verbal-Verbal & 1 & 2 & 2 & 3 & 3 & 5 & 2 & 7 \\
\hline & Verbal-Visual & 2 & 3 & 1 & 2 & 2 & 2 & 1 & 3 \\
\hline & Visual-Verbal & 8 & 8 & 8 & 8 & 8 & 8 & 8 & 8 \\
\hline & Visual-Visual & 1 & 3 & 0 & 2 & 2 & 4 & 2 & 4 \\
\hline & Recordação Verbal & 1 & 2 & 1 & 2 & 2 & 3 & 1 & 2 \\
\hline & Visual & & & & & & & & \\
\hline & Visual espacial & 2 & 4 & 2 & 6 & 3 & 8 & 3 & 6 \\
\hline & & \multicolumn{8}{|c|}{ Número Intervenções do Pesquisador durante a recontagem } \\
\hline & Rato Lua & \multicolumn{2}{|r|}{20} & \multicolumn{2}{|c|}{18} & \multicolumn{2}{|c|}{10} & \multicolumn{2}{|c|}{5} \\
\hline Histórias & Macaco Velha & \multicolumn{2}{|c|}{13} & \multicolumn{2}{|c|}{19} & \multicolumn{2}{|c|}{13} & \multicolumn{2}{|c|}{10} \\
\hline Infantis & Fazendeiro Filho & \multicolumn{2}{|c|}{17} & \multicolumn{2}{|c|}{39} & \multicolumn{2}{|c|}{10} & \multicolumn{2}{|c|}{8} \\
\hline & Burro Sal & \multicolumn{2}{|c|}{19} & \multicolumn{2}{|c|}{23} & \multicolumn{2}{|c|}{11} & \multicolumn{2}{|c|}{8} \\
\hline & Pulo Gato & \multicolumn{2}{|c|}{15} & \multicolumn{2}{|c|}{20} & \multicolumn{2}{|c|}{13} & \multicolumn{2}{|c|}{10} \\
\hline
\end{tabular}

Fonte: Dados da pesquisa.

A partir da distribuição da pontuação, na avaliação inicial e final de cada participante da pesquisa, percebe-se que todos os participantes apresentaram um desempenho melhor nos testes de avaliação da memória, depois da intervenção através das narrativas infantis. A média dos escores nos subtestes do TIMT e no Teste de Cubos de Corsi, avaliados depois da intervenção, obteve um aumento significativo. No subteste do visuo-espacial do TIMT e no Teste Cubos de Corsi, foi apresentada uma diferença ainda maior entre o escore da primeira avaliação e o da segunda avaliação. Diante disso, verifica-se que houve uma diferença entre médias no processo de avaliação de memória de trabalho antes e depois da intervenção realizada, principalmente, nos subtestes que envolvem a memória visuoespacial.

Diante das intervenções/mediações realizadas, apreende-se que os indivíduos CP e SB necessitaram de um maior número de mediações, se comparados com AR e RL. Dito de outra forma, CP e SB precisaram de maior número de intervenção para auxiliar no processo de recordação, para o encadeamento dos elementos das narrativas. Atrelado a este resultado, os resultados no Teste de Corsi, as participantes (CP e SB) tiveram desempenho inferior no teste, estes mesmos sujeitos necessitaram de um maior número de mediações no processo de recontagem das histórias. Dessa forma, fica evidente que a dificuldade na memória de trabalho também é inerente ao processo de recontagem em um episódio narrativo, ou seja, o processo de recordação tem relação direta com o desempenho na linguagem.

Com a apresentação das diferenças entre os escores na avaliação inicial e final, e o quantitativo das intervenções realizadas na recontagem das narrativas, evidencia-se que $\mathrm{CP}$ e 
SB precisaram de um maior número de intervenções e apresentaram menor pontuação tanto na avaliação de memória de trabalho inicial quanto na final, comparados com AR e LR. Além do mais, o desempenho na avaliação final foi superior ao processo de avaliação inicial em todos os participantes.

No processo de intervenção através das narrativas infantis, perceberam-se resultados importantes, que evidenciam a inter-relação da memória de trabalho e do desenvolvimento e expansão da linguagem oral nos indivíduos com SD. Na Tabela 3, exibe-se, no processo de recontagem dos participantes, a interdependência entre memória e linguagem oral, além de marcadores da expansão linguística:

Tabela 3 - Recontagem mediada das histórias

\begin{tabular}{|c|c|c|c|c|}
\hline Participante & $\begin{array}{c}\text { Primeira recontagem de } \\
\text { história }\end{array}$ & $\begin{array}{l}\text { Manifestação } \\
\text { Linguística }\end{array}$ & $\begin{array}{c}\text { Última recontagem de } \\
\text { história }\end{array}$ & $\begin{array}{l}\text { Manifestação } \\
\text { Linguística }\end{array}$ \\
\hline $\mathrm{CP}$ & $\begin{array}{c}\text { "Ratinho, lua, toca, no } \\
\text { quintal, o ratinho } \\
\text { sonhador ... Guloso." }\end{array}$ & $\begin{array}{c}\text { Fala telegráfica } \\
\text { sem encadeamento } \\
\text { lógico } \\
\text { Verbo sem flexão }\end{array}$ & $\begin{array}{c}\text { "Esperto ... Caiu no } \\
\text { rio." }\end{array}$ & $\begin{array}{c}\text { Expansão da fala com } \\
\text { encadeamento lógico. } \\
\text { Verbo flexionado }\end{array}$ \\
\hline RL & $\begin{array}{c}\text { Ia - Por que o burro cai } \\
\text { no rio de propósito? } \\
\mathrm{RL}-\text { Escorrega e cai. }\end{array}$ & Falta de abstração & $\begin{array}{l}\text { Aí o gato escorregou } \\
\text { no } \\
\text { telhado para pegar o } \\
\text { rato e aí ele deu um } \\
\text { pulo e pegou o rato. } \\
\text { Tamanduá viu tudo. }\end{array}$ & Presença de abstração \\
\hline SB & $\begin{array}{c}\text { Ia- E quem são esses } \\
\text { aqui? (aponta para } \\
\text { ilustração) } \\
\text { SB - Não sei. }\end{array}$ & $\begin{array}{c}\text { Sem apoio } \\
\text { visuoespacial }\end{array}$ & $\begin{array}{l}\text { Macaco ... Velha ... } \\
\text { Medo. (aponta para } \\
\text { ilustração) }\end{array}$ & Apoio visuoespacial \\
\hline AR & $\begin{array}{c}\text { O macaco roubava } \\
\text { banana da veia. Aí... } \\
\text { Veia colocou uma } \\
\text { armadilha para pegar o } \\
\text { macaco }\end{array}$ & $\begin{array}{l}\text { Presença do } \\
\text { conectivo "aí" }\end{array}$ & $\begin{array}{l}\text { O ratinho sentia o } \\
\text { cheiro do queijo e } \\
\text { imaginou que era a } \\
\text { lua. Ele sentia um } \\
\text { cheiro delicioso. }\end{array}$ & $\begin{array}{c}\text { Produz elementos } \\
\text { conectores, } \\
\text { encadeamento lógico, } \\
\text { abstração } \\
\text { e utiliza o apoio } \\
\text { visuoespacial. }\end{array}$ \\
\hline
\end{tabular}

Ia - Intervenções realizadas pelo pesquisador.

Com isso, nota-se que $\mathrm{CP}$, na primeira recontagem de uma narrativa, exibe uma produção oral bastante simplificada, caracterizada pelo estilo telegráfico, sem um encadeamento lógico dos acontecimentos presentes nas histórias. Essa não consegue expandir sua fala, uma vez que tem dificuldade na utilização de elementos de ligação, como conjunções, além de não utilizar verbos flexionados. Na última história recontada por $\mathrm{CP}$, 
percebe-se que esta consegue flexionar em seu léxico o verbo e utilizar conectivo, proporcionando uma melhor estruturação da fala em uma cadeia lógica de acontecimentos.

RL, por sua vez, na primeira recontagem da história, não consegue abstrair elementos da narrativa. Esta, quando questionada sobre a intenção do burro cair propositalmente no rio, demonstra não compreender que o objetivo do burro era se desfazer da carga pesada. Entretanto, na última recontagem de história, RL demonstra compreender elementos abstratos que auxiliam na compreensão de toda a narrativa.

SB, inicialmente, não apresenta apoio visuoespacial, porém, na última recontagem, esta já utiliza do apoio visuoespacial para auxiliar na recordação da narrativa. O apoio visual oferece pistas para a recuperação de informações da narrativa. Além do mais, quando se associam elementos visuais e fonológicos, têm-se dois caminhos para acessar e recuperar dados mnemônicos. Dessa forma, a integração da percepção visuoespaciais, junto a aspectos fonológicos, aumenta as chances de recordações mnemônicas, o que é uma estratégia compensatória para indivíduos com dificuldades na memória de trabalho.

Por fim, AR emite a progressão sequencial "aí" como elemento de relação entre os eventos da história, na primeira recontagem, o que auxilia no encadeamento lógico do enredo da narrativa. O operador "aí" tem como objetivo ligar dois ou mais acontecimentos de uma narrativa, corroborando para melhor entendimento do enredo da narrativa. Na última recontagem de história, AR demonstra ter um desempenho favorável na mesma, exibe indícios imaginativos de episódios, que não ocorreram na narrativa. Assim, AR generaliza o conhecimento, uma vez adquirido para outra história, ou seja, a criança já consegue abstrair e construir a própria linguagem.

\section{Discussões}

Compreende-se, através da apresentação dos dados, que, na avalição inicial, as crianças e adolescentes com SD exibiram um desempenho maior que os iniciais, depois do processo de intervenção. Confirmando a hipótese inicial de que o processo de intervenção, através das histórias infantis, desencadeia um bom desempenho na memória de trabalho, atrelado à expansão da linguagem. Percebe-se, com isso, que os participantes apresentaram um melhor desempenho em tarefas que exigem o elemento visuoespacial no processo de 
recordação, se comparadas à tarefa com apenas o apoio visual e verbal. Nas pesquisas desenvolvidas por Laws (2002), Chapman (2006) e Duarte (2009), esses autores também afirmam que os indivíduos com SD exibem melhores desempenhos em contextos nos quais há um apoio visuoespacial.

Entretanto, os participantes da pesquisa, apresentaram maiores dificuldades para integração e manipulação de informações verbais. Nos subtestes que envolvem o apoio verbal, os indivíduos não obtiveram um bom desempenho, se comparado ao subteste com o elemento visuoespacial. No mesmo estudo de Duarte (2009), salienta-se a dificuldade na utilização da expressão verbal, encontrada em crianças com SD. Esses sujeitos apresentam um desemparelhamento na compreensão de um ato de fala e também na linguagem oral, além de exibirem prejuízos em reconhecer as regras gramaticais e sintáticas da língua. Por isso, nos aspectos morfológicos, sintáticos, semânticos, prosódicos e fonológicos de uma língua, os indivíduos com SD apresentam atrasos como um todo. Já que os aspectos da língua se interagem entre si dentro de um contexto de fala e escrita.

Pesquisas apontadas por Duarte (2009) mostram como resultados que indivíduos com SD apresentam um desempenho similar ao grupo controle sem síndrome, pareados pelo mesmo nível de inteligência, em tarefas que envolvem características da memória visuoespacial. Porém, no aspecto da alça fonológica, esses indivíduos exibem uma performance inferior ao grupo controle. Portanto, deve-se considerar que, como vulnerabilidade, os sujeitos com SD têm no componente da alça fonológica, mas como potencialidade, apresentam o aspecto visuoespacial. Assim sendo, o manejo das potencialidades, perante as vulnerabilidades, faz com que esses indivíduos perpassem as dificuldades características da síndrome, no processo de memória de trabalho e linguagem. Aliás, esses processos cognitivos auxiliam na internalização dos elementos da narrativa e a elaboração de pensamentos abstratos.

Pode-se conjecturar, dessa forma, que no processo de memorização, tem-se o auxílio de elementos visuoespaciais e fonológicos, integrados aos elementos episódicos, denominados por Baddeley (2011) como buffer episódico. Dessa maneira, as ilustrações contidas nas histórias, os gestos, a entonação e o ritmo da leitura favorecem a memorização. Além disso, o processo de armazenamento é melhor quando a informação é apresentada em um episódio, e, por isso, as narrativas infantis são importantes ferramentas para trabalhar tanto a linguagem oral como a memória em crianças com SD. 
Ademais, para que um indivíduo possa conseguir elaborar um pensamento lógico a respeito da narrativa, é necessário que ele armazene informações para, posteriormente, evocar e elaborar um pensamento que envolva encadeamento dos fatos. Nos participantes da pesquisa com maior dificuldade na memória de trabalho, o processo de recontagem de uma história aconteceu com certa dificuldade em conseguir encadear os fatos da história, ou seja, compreender que um fato está ligado a outro, e assim por adiante. Essa dificuldade ocasiona prejuízos na recontagem da história e no entendimento dos elementos abstratos contidos na narrativa.

A constituição de frases em uma cadeia lógica de acontecimentos possibilita maiores possibilidades de armazenamento das informações. Em um episódio, contém a integração de elementos visuoespaciais, fonológicos, em conjunto com aspectos da memória de longo prazo. Essa junção de diversos elementos pode proporcionar maior armazenamento do conteúdo de uma narrativa. Além disso, a estrutura sintática com o encadeamento de palavras dentro de uma frase, regidas por um sistema de regras, possibilita maior compreensão de um episódio narrativo, e requer elementos da memória de longo prazo. Segundo Baddeley (2011), a ordem das palavras dentro da frase é restrita por regras gramaticais e pelo sentido geral da frase, ambas permitindo o processo de blocos, que depende de sequências de letras consistentes a hábitos de linguagem de longa duração. Dessa maneira, é através da organização linguística que um evento se estabelece e encontra relações lógicas, o que significa que trazer algo à memória, baseia-se na descoberta de um aspecto que precisa ser encontrado e estruturado através da linguagem. Assim, o encadeamento de fatos com sentido lógico possibilita que o indivíduo associe dimensões fonológicas e visuoespaciais com a memória de longo prazo.

Diante das intervenções/mediações realizadas, apreende-se que os indivíduos CP e SB necessitaram de um maior número de mediações e apresentaram menor pontuação tanto na avaliação inicial quanto na final, se comparados com AR e LR. Os participantes com menor performance narrativa exibiram, na recontagem das histórias, elementos iniciais do processo de aquisição da narrativa, como fala telegráfica, dificuldade na utilização de elementos de ligação, como as conjunções, verbos inflexionados e falta de abstrações. Já os participantes com melhor desempenho narrativo utilizavam marcadores linguísticos, verbos flexionados, apoio visuoespacial e o entendimento de elementos abstratos das histórias. 
A fala telegráfica ou simplificada é descrita por Abaurre e Coudry (2008) como um discurso econômico, constituído, na maioria das vezes, apenas por palavras essenciais. O sujeito não consegue expandir sua fala, uma vez que tem dificuldade na utilização de elementos de ligação, como conjunções, o que prejudica o encadeamento lógico presente em narrativas e, por conseguinte, a falta de abstração. No "estilo telegráfico", a criança omite alguns elementos, a produção oral é simplificada e parecida com um telegrama. Essa fala é limitada a um substantivo e um verbo e, geralmente, contém pouca ou nenhuma classe gramatical auxiliar. Dessa forma, a não expansão da fala, dentro de um processo narrativo, acarreta falta de organização dos conteúdos em uma cadeia lógica.

É importante destacar que, segundo Ghirello-Pires e Labigalini (2010), a produção oral simplificada torna-se uma estratégia para a dificuldade no desenvolvimento da linguagem em indivíduos com SD. Conforme Scarpa (2001), as crianças com SD perpassam os mesmos processos de aquisição da linguagem pelos quais passam as crianças sem a síndrome, contudo, de maneira mais lenta. Assim, é importante interpretar que essa economia de palavras é característica do processo de aquisição da linguagem tanto em indivíduos típicos como atípicos. Nesse sentido, a fala simplificada é caracterizada como uma fase de desenvolvimento da linguagem, e a superação dessa fase faz com que a criança adquira um discurso oral mais complexo, abrangendo a formação de frases e inter-relacionando-as.

Além disso, a falta no vocabulário linguístico de verbos flexionados corrobora para a dificuldade no encadeamento lógico em uma narrativa. A utilização da categoria verbal faz com que os personagens desenvolvam ações, pois o verbo desempenha a ação complicadora de uma narrativa. Além do mais, a presença do o marcador de convenção de abertura de uma história "Era uma vez", em que Perroni (1992) cita o estudo de Applebee (1978), evidencia que nas narrativas há um uso consistente de tempo passado, a aceitação de personagens e eventos fictícios e a possibilidade de incorporar certos tipos de personagens e situações convencionais.

Ademais, a emissão da progressão sequencial "aí", como elemento de relação entre os eventos da história, auxilia no encadeamento lógico do enredo da narrativa. Além do elemento visuoespacial, o que faz com que os indivíduos com SD apresentem melhores desempenhos na recordação, colaborando para um bom desempenho no processo narrativo. Dessa forma, o percurso processual de narrar uma história associa elementos de memória de trabalho, 
relacionados à produção oral, que envolve questões temporais, com a flexão de verbos, aos elementos associativos, que são as conjunções que auxiliam no encadeamento de eventos.

Percebe-se que, então, na medida em que a intervenção foi sendo desempenhada, todos os participantes da pesquisa apresentaram desempenhos significativos nos processos de linguagem. Diante disso, a atividade de contagem e recontagem das narrativas infantis é um mecanismo dinâmico de construção da linguagem e do pensamento. Através da situação trazida pela história, são abordados os seguintes aspectos: a língua, o enredo, as relações sociais, os valores culturais e o simbolismo que remete à afetividade. Dito de outra forma, a habilidade de narrar uma história estimula conjuntamente a habilidade verbal (linguagem), a cognição (e neste estudo delimitou-se por estudar apenas a memória) e as relações socioculturais. Assim, a atividade de contar e recontar histórias constitui um mecanismo de aprendizagem, uma vez que amplia o conhecimento da criança em nível de produção oral, vocabulário, memória e pensamento abstrato.

Durante o processo de recontagem das histórias, o trabalho linguístico realizado pelo pesquisador foi fundamental para que a criança/adolescente pudesse organizar sintaticamente os enunciados apresentados, com o objetivo de auxiliar no desenvolvimento do pensamento. Segundo Perroni (1992), as perguntas que o interlocutor faz ajudam na construção processual da narrativa, e é através dessa interação que a criança lembra, através da forma de discurso, o que ela pretende contar. Diante disso, é importante salientar o papel da interação da criança com o interlocutor no auxílio do processo interventivo tanto no processo de rememoração de elementos da história, como também na expansão da linguagem oral.

Como apresentado nos resultados, os indivíduos com trissomia 21 apresentam uma grande variabilidade no desempenho de funções cognitivas, e não há um padrão único entre esses sujeitos, pois além da alteração cromossômica, existem importantes influências do meio. O ambiente com estimulações positivas é um fator decisivo para o desenvolvimento cognitivo, principalmente a memória de trabalho, que é um aspecto cognitivo desenvolvido através do seu uso (BADDELEY, 2011). O cérebro é que apresenta uma capacidade plástica, porém, para que a neuroplasticidade ocorra de maneira mais efetiva, é necessário promover uma estimulação direcionada.

Dessa forma, o trabalho desenvolvido de estimulação da memória de trabalho, por meio das mediações/intervenções do pesquisador na recontagem das narrativas infantis, pode provocar uma melhora na memória de trabalho, o que acarretou, também, uma 
consequentemente melhora no funcionamento da linguagem. Por isso, a importância de uma estimulação externa, que provoque aprendizagem e favoreça mudanças em áreas associadas à memória e à linguagem. Assim, o ambiente estimulador pode favorecer o desempenho das crianças/adolescentes com SD em atividades que requerem o uso da memória de trabalho através da linguagem oral.

\section{Conclusão}

A tarefa de contagem e recontagem de uma história infantil é uma ferramenta para a estimulação da memória de trabalho, por meio da linguagem, uma vez que o elemento do buffer episódio integra as informações fonológicas, visuais e espaciais que são importantes para um processo narrativo. As histórias são compostas por diversos elementos, que interferem na constituição da linguagem, inclusive a memória de trabalho, sendo necessária a memorização de elementos presentes na história para poder interpretá-la de maneira adequada. Além disso, através da narrativa, é possível expandir o desempenho linguístico e fazer a internalização do conteúdo abstrato. Dessa maneira, a intervenção proposta com as crianças e adolescentes com SD sugere que a estimulação da memória de trabalho, por meio da linguagem no contexto da contagem e recontagem das histórias infantis, obteve influência no armazenamento de informações e no desenvolvimento da linguagem oral.

Os resultados sugerem que os participantes do estudo tiveram desempenhos significativos na avaliação final da memória de trabalho, em comparação à avaliação inicial, o que indica que o processo interventivo, através das narrativas, favoreceu o desempenho do raciocínio lógico e abstrato, a partir da inter-relação dos dois processos cognitivos complexos, memória e linguagem. Por meio do processo interventivo, percebeu-se uma variabilidade no desempenho da recontagem da história, nos processos de desenvolvimento de fala, na narrativa com o encadeamento lógico dos eventos, em elementos de rememoração e de desenvolvimento linguístico. Essa variabilidade na performance narrativa se conjetura com a própria característica da $\mathrm{SD}$, que apresenta uma variabilidade cognitiva e, consequentemente, diferenças comportamentais. Portanto, deve-se considerar que existem diferenças biológicas, sociais e psicológicas nos indivíduos com SD. 
Além disso, a interação do interlocutor (pesquisador) com o locutor (participante) proporcionou expansão processual da habilidade de narrar, além de auxiliar na estruturação da narrativa em uma cadeia lógica de acontecimentos, que desencadeou aumento no armazenamento de conteúdos mnemônicos e sua posteriormente reverberação. Nota-se também que, nos indivíduos com SD, o conteúdo visuoespacial pode ser utilizado como recurso na aprendizagem, já que proporciona melhores desempenhos no processo de memorização de conteúdo. Além disso, a causalidade dos eventos de uma narrativa possibilitou compreender elementos abstratos, com avanços consideráveis na capacidade para perceber e encadear as relações entre fenômenos e elementos abstratos.

Vale ressaltar que os indivíduos com SD apresentam uma condição neurobiológica, que interfere significativamente na linguagem e na memória, porém os resultados evidenciaram que, com uma intervenção direcionada, as crianças e adolescentes com SD expandiram o repertório linguístico, e isso auxiliou no processo de memória de trabalho. Dessa forma, compreende-se a capacidade espetacular do organismo humano em se modificar frente os estímulos, uma vez que a plasticidade cerebral está relacionada à qualidade, duração e forma de estimulação que recebe o indivíduo com a síndrome.

Ademais, considerar que sujeitos com SD podem ter seu pleno desenvolvimento, mesmo com as dificuldades inerentes, é fundamental para uma postura interventiva. O nível de comprometimento cognitivo na população com SD poderia justificar a dificuldade na linguagem e memória, entretanto, como podemos observar, o trabalho de contagem e recontagem favorece a produção de linguagem oral em conjunto com a memória.

\section{Referências}

ABAURRE, M. B.; COUDRY, M. I. H. Em torno de sujeitos e olhares. Estudos da Língua(gem), Vitória da Conquista, v. 6, n. 2, p. 171-191, 2008. Disponível em: http://www.estudosdalinguagem.org/index.php/estudosdalinguagem/article/view/100/210. Acesso em: 17 de agosto de 2017.

ANGElini, A. L. et al. Matrizes Progressivas Coloridas de Raven: Escala Especial. Manual. São Paulo: CETEPP, 1999.

ASSOCIAÇÃO BRASILEIRA DE EMPRESAS DE PESQUISA. Critério de classificação econômica Brasil. Disponível em: http://www.abep.org/criterio-brasil. Acesso em: $17 / 07 / 2016$. 
BADDELEY, A. D.; JARROLD, C. Working memory and Down syndrome. Journal of Intellectual Disability Research, S/I, v. 51, n. 12, p. 925-931, 2007.

BADDELEY, A. D. Memória de Trabalho. In: BADDELEY, A. D.; ANDERSON, M.; EYSENCK, M. Memória. Porto Alegre: Artmed, 2011. p. 54-82.

BISSOTO, M. L. O desenvolvimento cognitivo e o processo de aprendizagem do portador de Síndrome de Down: revendo concepções e perspectivas educacionais. Ciências \& Cognição, Rio de Janeiro, v. 4, n. 2, p. 80-88, 2005. Disponível em: http://www.cienciasecognicao.org/revista/index.php/cec/article/view/485/262. Acesso em: 24 de setembro de 2017.

BRUNER, J. Actos de significado. Lisboa: Edições 70, 2008.

CAMARGO, E. A. A. Era uma vez... o contar histórias em crianças com síndrome de Down. 1994. 110 fls. Dissertação (Mestrado em Linguística). Instituto de Estudo da Linguagem Universidade Estadual de Campinas, Campinas, 1994.

CAPELI, A.; DIAS, D. Coleção Lua de Papel. Editora FTD, 2009.

CHAPMAM, R.S. Language learning in Down Sydrome: the speech and language profile compared to adolescents with cognitive impairment of unknown origin. Down Syndrome Research and Pratice, S/I, v. 10, n. 2, p. 61-66, 2006. Disponível em: https://www.downsyndrome.org/reports/306/reports-306.pdf. Acesso em: 08 de agosto de 2017.

CUNNINGHAM, C. Síndrome de Down: Uma Introdução para pais e cuidadores. Porto Alegre: Phorte, 2008.

DUARTE, $C . P$. Caracterização do perfil cognitivo e avaliação da memória de trabalho na síndrome de Down. 2009. Dissertação (Mestrado), Instituto de Distúrbios do Desenvolvimento - Universidade Presbiteriana Mackenzie, 2009. f. 01-97.

GHIRELLO-PIRES, C. S. A. A inter-relação fala, leitura e escrita em duas crianças com síndrome de Down. 2010. 130f. Tese (Doutorado em Linguística). Instituto de Estudos da Linguagem - Universidade Estadual de Campinas, Campinas, 2010.

GHIRELLO-PIRES, C. S. A. Síndrome de Down e Linguagem: caminhos para a autonomia. In: VII SEMINÁRIO DE PESQUISA EM ESTUDOS LINGUÍSTICOS. Anais [...]. Vitória da Conquista: Periódicos UESB, v. 7, n. 1, 2012.

JARROLD, C.; NADEL, L.; VICARI, S. Memory and neuropsychology in Down syndrome. Down Syndrome Research and Practice, S/I, v. 12, n. 3, p. 68-73, 2008. Disponível em: https://www.down-syndrome.org/reviews/2068/reviews-2068.pdf. Acesso em: 09 de julho de 2017.

KOZMA, C. O que é Síndrome de Down. In: STRAY-GUNDERSEN, K. (Org). Crianças com Síndrome de Down: guia para pais e educadores. Porto Alegre: Artmed, 2007. 
LAWS, G. Working memory in children and adolescents with Down syndrome: evidence from a colour memory experiment. Journal of Child Psychology andPsychiatry, S/I, v. 43, n. 3, p. 353-364, 2002.

PERRONI, Maria Cecília. O desenvolvimento do discurso narrativo. São Paulo: Martins Fontes, 1992.

PINTER, et al. Amygdala and hippocampal volumes in children with Down syndrome: a high-resolution MRI study. Neurology, apr. 10; 56(7), p. 972-4, 2001.

SALES S.; KONKIEWITZ E. C. Tópicos de neurociência clínica. Reabilitação neuropsicológica. Dourados, MS: Editora da UFGD, 2010.

SCARPA, E. M. Aquisição da Linguagem. In: MUSSALIM, F; BENTES, A. C. (Orgs.). Introdução à linguística: domínios e fronteiras. São Paulo: Cortez, 2001. p. 203-232.

SCHWARTZMAN, J. S. Síndrome de Down. São Paulo: Memnon, 2003.

SILVA, M. F. M. C.; KLEINHANS, A. C. P. Processos cognitivos e plasticidade cerebral na Síndrome de Down. Revista Brasileira de Educação Especial, Marília, v. 12, n. 1, p. 123138, 2006. Disponível em: http://www.scielo.br/scielo.php?script=sci_arttext\&pid=S141365382006000100009\&lng=en\&nrm=iso. Acesso em: 07 de junho de 2017.

SILVERMAN, W. Down syndrome: cognitive phenotype. Mental Retardation and Developmental Disabilities Research Reviews, S/I, v. 13, n. 3, p. 228-236, 2007.

Síndrome de Down. Dissertação (Mestrado em Distúrbios do Desenvolvimento).

SPINNLER H.; TOGNONI, G. S. Di test neuropsicologici. The Italian Journal of Neurological Sciences, 1987.

TRONCOSO, V. M.; CERRO, M. M. Síndrome de Down: lectura y escritura. Barcelona: Masson, 1999.

\section{Como citar este artigo (Formato ABNT):}

LIMA, Amanda Avelar; GHIRELLO-PIRES, Carla Salati Almeida. Desenvolvimento da Linguagem Oral e da Memória de Trabalho em Indivíduos com Síndrome de Down por meio da Recontagem de Histórias. Id on Line Rev.Mult. Psic., 2019, vol.13, n.46, p. 212-230. ISSN: 1981-1179.

Recebido: 16/05/2019

Aceito 10/06/2019 